\title{
Photocatalytic Degradation of Methylene Blue under UV Light Irradiation on Prepared Carbonaceous $\mathrm{TiO}_{2}$
}

\author{
Zatil Amali Che Ramli, ${ }^{1}$ Nilofar Asim, ${ }^{1}$ Wan N. R. W. Isahak, ${ }^{2}$ Zeynab Emdadi, \\ Norasikin Ahmad-Ludin, ${ }^{1}$ M. Ambar Yarmo, ${ }^{2}$ and K. Sopian ${ }^{1}$ \\ ${ }^{1}$ Solar Energy Research Institute, Universiti Kebangsaan Malaysia, 43600 Bangi, Selangor, Malaysia \\ ${ }^{2}$ School of Chemical Science \& Food Technology, Faculty of Science and Technology, Universiti Kebangsan Malaysia, \\ 43600 Bangi, Selangor, Malaysia \\ Correspondence should be addressed to Nilofar Asim; asimnilofar@gmail.com
}

Received 6 February 2014; Accepted 7 May 2014; Published 11 June 2014

Academic Editor: Liqiang Jing

Copyright (C) 2014 Zatil Amali Che Ramli et al. This is an open access article distributed under the Creative Commons Attribution License, which permits unrestricted use, distribution, and reproduction in any medium, provided the original work is properly cited.

\begin{abstract}
This study involves the investigation of altering the photocatalytic activity of $\mathrm{TiO}_{2}$ using composite materials. Three different forms of modified $\mathrm{TiO}_{2}$, namely, $\mathrm{TiO}_{2} /$ activated carbon (AC), $\mathrm{TiO}_{2} /$ carbon (C), and $\mathrm{TiO}_{2} / \mathrm{PANi}$, were compared. The TiO$/$ carbon composite was obtained by pyrolysis of $\mathrm{TiO}_{2} / \mathrm{PANi}$ prepared by in situ polymerization method, while the $\mathrm{TiO}_{2} /$ activated carbon $\left(\mathrm{TiO}_{2} / \mathrm{AC}\right)$ was obtained after treating $\mathrm{TiO}_{2} /$ carbon with $1.0 \mathrm{M} \mathrm{KOH}$ solution, followed by calcination at a temperature of $450^{\circ} \mathrm{C}$. $\mathrm{X}$-ray powder diffraction (XRD), transmission electron microscopy (TEM), Fourier transform infrared (FTIR), thermogravimetric analysis (TG-DTA), Brunauer-Emmet-Teller (BET), and UV-Vis spectroscopy were used to characterize and evaluate the prepared samples. The specific surface area was determined to be in the following order: $\mathrm{TiO}_{2} / \mathrm{AC}>\mathrm{TiO}_{2} / \mathrm{C}>\mathrm{TiO}_{2} / \mathrm{PANi}>\mathrm{TiO}{ }_{2}(179>134$ $>54>9 \mathrm{~m}^{2} \mathrm{~g}^{-1}$ ). The evaluation of photocatalytic performance for the degradation of methylene blue under UV light irradiation was also of the same order, with $98>84.7>69 \%$ conversion rate, which is likely to be attributed to the porosity and synergistic effect in the prepared samples.
\end{abstract}

\section{Introduction}

Currently, the rapid industrialization in developing countries has begun to introduce harmful organic pollutants into the water supply. These effluents are also sourced from the textile industry that consumes a large quantity of water in the process of dyeing and washing of fabrics and the release of huge quantities of dyes [1]. Therefore, the development of inexpensive and green methods to treat and purify contaminated water has been the focal subject in technological developments. Among many strategies, photocatalysis is regarded as the most viable one, especially for treatment of contaminants, due to its usage of sunlight to decompose organic pollutants [2-4]. Titanium dioxide or titania $\left(\mathrm{TiO}_{2}\right)$ acts as an agent in this process $[5,6]$. However, $\mathrm{TiO}_{2}$ is not without its drawback in the context of photocatalysis, such as its high band gap energy $3.2 \mathrm{eV}$ for anatase [7], the limitation of photo response only under UV light region, and its high rate of electron and hole recombination. Attempts to address these problems involve doping, nonmetallic elements doping, surface modification, forming composites with narrow semiconductors, using semiconductor polymer as support, and coating with carbon layers to improve and enhance the photocatalytic activity of titanium dioxide.

Current literature shows that activated carbon is gaining attention as it is capable of modifying $\mathrm{TiO}_{2}$ photocatalyst. The work in [8-12] showed that this enhancement is caused by porous structure of activated carbon, which provides a large surface area for photoactive $\mathrm{TiO}_{2}$ particle.

The work in $[8,13-15]$ found the synergistic effect of the mixture of $\mathrm{TiO}_{2}$ with activated carbon (AC). The improvement of $\mathrm{TiO}_{2} / \mathrm{AC}$ composite was explained by the high adsorption of the impurities on the surface of activated carbon and their transfer to the $\mathrm{TiO}_{2}$ surface. In this study, carbonaceous $\mathrm{TiO}_{2}$, namely, $\mathrm{TiO}_{2}$ /activated carbon (AC), $\mathrm{TiO}_{2} /$ carbon $(\mathrm{C})$, and $\mathrm{TiO}_{2} / \mathrm{PANi}$ were prepared and 
evaluated for photocatalytic performance for degradation of methylene blue under UV light irradiation. The carbon and activated carbon/ $/ \mathrm{TiO}_{2}$ were synthesized using polyaniline (PANi) as its carbon source.

\section{Experimental and Characterizations}

2.1. Preparation of $\mathrm{TiO}_{2} /$ Polyaniline and $\mathrm{TiO}_{2} /$ Carbon. $\mathrm{TiO}_{2} /$ polyaniline $\left(\mathrm{TiO}_{2} / \mathrm{PANi}\right)$ was synthesized using $\mathrm{TiO}_{2}$ (Sigma Aldrich, 99.9\% purity) and aniline hydrochloride (Sigma Aldrich, 99.95\%). In order to synthesize $\mathrm{TiO}_{2} / \mathrm{PANi}$, $0.2 \mathrm{~mol} \mathrm{~cm}^{-3}$ aniline hydrochloride solution was prepared by adding $259 \mathrm{mg}$ aniline hydrochloride to $5 \mathrm{~mL}$ deionized water and was vigorously stirred for 10 minutes at a temperature of $60^{\circ} \mathrm{C}$. $\mathrm{TiO}_{2}$ powder, with various percentages $(5 \%$, $10 \%$ and $15 \%)$, is added to aniline hydrochloride solution being prepared previously. $0.25 \mathrm{~mol} \mathrm{~cm}^{-3}$ ammonium peroxydisulphate solution was prepared by adding $571 \mathrm{mg}$ ammonium peroxydisulphate (Sigma Aldrich, 98\% reagent grade) in $5 \mathrm{~mL}$ deionized water. While the mixture above was being stirred, the prepared ammonium peroxydisulphate solution was added to the mixture and was stirred for an additional 10 minutes. The polymerization was completed in about 10 minutes. The solution was then left to dry at room temperature for 48 hours. The precipitate powder was then centrifuged and washed with absolute ethanol, followed by distilled water in order to remove unreacted aniline monomer and its corresponding by-products. The product $\left(\mathrm{TiO}_{2} / \mathrm{PANi}\right)$ was dried at $65^{\circ} \mathrm{C}$ for $24 \mathrm{~h}$. The composite that was the result of the process was labeled as $\mathrm{TiO}_{2} / \mathrm{PANi}$. The product was then pyrolyzed at a temperature of $450^{\circ} \mathrm{C}$ for 1 hour in nitrogen flow at a heating rate of $10^{\circ} \mathrm{C} \mathrm{min}{ }^{-1}$ to produce titania/carbon $\left(\mathrm{TiO}_{2} / \mathrm{C}\right)$.

2.2. Chemical Activation of $\mathrm{TiO}_{2} /$ Carbon. In order to produce porous carbon or the so-called activated carbon, the $\mathrm{TiO}_{2} / \mathrm{C}$ was treated with $1.0 \mathrm{M} \mathrm{KOH}$ solution. About $0.3 \mathrm{~g} \mathrm{TiO} / \mathrm{C}$ was mixed with $2.5 \mathrm{~mL} 1.0 \mathrm{M} \mathrm{KOH}$ solution. The mixture was then heated at a temperature of $450^{\circ} \mathrm{C}$ under nitrogen gas flow for 1 hour. Then the treated sample was washed with deionized water until it was neutral and dried overnight at a temperature of $100^{\circ} \mathrm{C}$ and was labeled $\mathrm{TiO}_{2} / \mathrm{AC}$. Since the early photocatalytic performance tests demonstrated better result for the $\mathrm{TiO}_{2} / \mathrm{AC}$ prepared from $15 \% \mathrm{TiO}_{2} / \mathrm{PANi}$, the characterization was done for $15 \% \mathrm{TiO}_{2} / \mathrm{PANi}$ and the resulting $\mathrm{TiO}_{2} / \mathrm{C}$ and $\mathrm{TiO}_{2} / \mathrm{AC}$ (hereafter denoted as $\mathrm{TiO}_{2} / \mathrm{PANi}$, $\mathrm{TiO}_{2} / \mathrm{C}$, and $\mathrm{TiO}_{2} / \mathrm{AC}$, resp.).

2.3. Characterizations. The functionality groups of the samples were determined using FTIR spectra. The morphology and structure of the samples were determined by field emission scanning electron microscope (FESEM, ZEISS Supra VP55) and transmission electron microscope (JEOL JEM2100). The specific surface area, pore size, pore volume, and pore diameter of the samples were determined by BrunauerEmmet-Teller (BET) method [16] using a nitrogen adsorption instrument (Micrometics ASAP 2010). The samples were degassed at $100^{\circ} \mathrm{C}$ for 24 hours prior to the analysis. Pore size distribution was calculated from the adsorption desorption of the isotherms using the Barret-Joyner-Halenda (BJH) model [17], while the crystallinity of the samples was analyzed using Brucker DB-advance X-ray diffractometer (XRD). The analyses were done under the setting of $\mathrm{Cu} k \alpha$ radiation at 2 theta, ranging from $10^{\circ}$ to $80^{\circ}$ for a 1-gram sample. The particle size of the sample was calculated by applying Scherrer's equation. Thermal gravimetric analysis (TGA) with a simultaneous TGA-DTG system (model: Mettler Toledo) has been used for investigation of thermal stability of samples. To reduce the influence of the sample quantity on the analyses, $5 \pm 0.2 \mathrm{mg}$ of each sample was used in each analysis with a constant nitrogen $\left(\mathrm{N}_{2}\right)$ flow $50.0 \mathrm{~mL} \mathrm{~min}^{-1}$ maintained throughout the entire process. To minimize possible differences in the moisture content between samples, all TGA samples were equilibrated at $50^{\circ} \mathrm{C}$ for $5 \mathrm{~min}$ before being heated to $700^{\circ} \mathrm{C}$ at a ramping rate of $5^{\circ} \mathrm{C} \mathrm{min}^{-1}$.

For investigation of prepared samples recyclability, the used catalyst was separated from reaction mixture by filtration. After that, it is washed with distilled water several times and dried in oven to be reused for next reaction cycle. Then they were used for subsequent cycles under similar reaction conditions as carried out by fresh catalyst.

2.4. Photocatalytic Experimental. The photocatalytic activities of the samples were evaluated via the photocatalytic oxidation of methylene blue (MB) under UV light irradiation. A 15 watt UV bench lamp was used as a light source. Since the photocatalytic test took into account different $\mathrm{MB}$ concentrations $(0.05,0.1$, and $0.15 \mathrm{mM})$ and different irradiation times, it showed better results for $0.05 \mathrm{mM}$ and 90 minutes, respectively, and was selected as the test condition (see Section 3.2).

Prior to illumination, $20 \mathrm{mg}$ photocatalyst was added to the $\mathrm{MB}$ solution $(20 \mathrm{~mL}, 0.05 \mathrm{mM})$. The solution was stirred in the dark for 30 minutes in order to reach $\mathrm{MB}$ absorption-desorption equilibrium, which will then allow for the commencement of the photocatalytic reaction. The photocatalyst will then be exposed to the UV lamp for 90 minutes in room temperature. The results after this time period will be evaluated after 90 minutes.

The degradation efficiency of MB was analyzed using UVVis spectrometer. Peaks were observed to be present between 600 and $700 \mathrm{~nm}$ and were assigned as the absorption of the $\pi$-system [18], which was indicative of the degradation of MB. According to Beer-Lambert Law, MB's concentration is directly proportional to its absorbance. This makes it possible to determine the oxidation efficiency of $\mathrm{MB}$ using the following equation:

$$
R=\frac{\left(C_{o}-C_{t}\right)}{C_{o}} \times 100 \% \text {, }
$$

where $C_{o}$ is the initial concentration of $\mathrm{MB}$ solution and $C_{t}$ is concentration of $\mathrm{MB}$ during irradiation. 


\section{Results and Discussions}

The existence of polyaniline on the $\mathrm{TiO}_{2}$ surface particle was verified by IR spectra. The characteristic bands of $\mathrm{TiO}_{2}$, polyaniline (made in the same way for comparison purpose only), $\mathrm{TiO}_{2} / \mathrm{PANi}$, and $\mathrm{TiO}_{2} / \mathrm{AC}$ are shown in Figures $1(\mathrm{a})$, 1(b), 1(c), and 1(d), respectively. The FTIR spectrum of polyaniline was clearly observed in $\mathrm{TiO}_{2} / \mathrm{PANi}$ sample. The spectra display the two bands at 1490 and $1585 \mathrm{~cm}^{-1}$, which were assigned to benzenoid and quinoide rings. The band at $1300 \mathrm{~cm}^{-1}$ is related to $\mathrm{C}-\mathrm{N}$ stretching of a secondary aromatic amine, while the band at $1140 \mathrm{~cm}^{-1}$ is attributed to the vibration mode of the polymer. These bands reveal the existence of PANi in the synthesized $\mathrm{TiO}_{2} / \mathrm{PANi}$ sample. In $\mathrm{TiO}_{2}$ and $\mathrm{TiO}_{2} / \mathrm{AC}$ spectra, peaks around $3400 \mathrm{~cm}^{-1}$ were assigned to $-\mathrm{OH}$ stretching, while those at $1600 \mathrm{~cm}^{-1}$ were assigned to $-\mathrm{OH}$ vibration. These peaks can be attributed to the adsorbed water from the environment.

The morphologies and size of the prepared nanoparticles were studied by variable pressure scanning electron microscope (VPSEM) and transmission electron microscopy (TEM) (Figures 2 and 3 ).

From the TEM image of Figure 3(a), it was shown that bare $\mathrm{TiO}_{2}$ particles are uniform in shape, with sizes ranging from 25 to $30 \mathrm{~nm}$. Figure 3(b) shows $\mathrm{TiO}_{2} / \mathrm{PANi}$ composite, where the sizes range from 30 to $40 \mathrm{~nm}$. Both TEM and FESEM photographs show that there is no significant difference of particle size of the samples $\mathrm{TiO}_{2} / \mathrm{C}$ and $\mathrm{TiO}_{2} / \mathrm{AC}$ (before and after chemical activation of $\mathrm{KOH}$ solution) (40$80 \mathrm{~nm}$ ). This agrees with previous studies, which reported that the sintering effect did not occur for $\mathrm{TiO}_{2} /$ carbon after being heated at temperatures below $700^{\circ} \mathrm{C}$ [19].

The XRD patterns of the prepared samples were shown in Figure 4 . The main diffraction peaks were at $25.3^{\circ}, 37.8^{\circ}, 48^{\circ}$, $54^{\circ}$, and $62.6^{\circ}$, assigned to the diffraction planes of $\left(\begin{array}{lll}1 & 0 & 1\end{array}\right),(0$

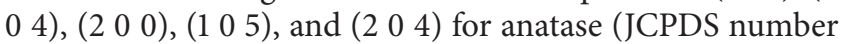
021-1272), respectively. Other crystal phases corresponding to the peaks at 27.4 and $36.1^{\circ}$ were assigned to the diffraction peaks of (1 110$)$ and (1 01 1) of rutile (JCPDS number 021-1276), respectively. The XRD patterns revealed the diffraction peaks of a mixture of anatase and rutile in the prepared samples, which is favorable for photocatalytic reactions [20-23]. XRD also showed that the preparation of $\mathrm{TiO}_{2}$ composites did not affect the crystal structure of $\mathrm{TiO}_{2}$, but the peaks intensity became lower and its shape got wider, especially in the case of $\mathrm{TiO}_{2} / \mathrm{PANi}$. This can be attributed to certain crystalline structure in PANi overlapping $\mathrm{TiO}_{2}$ peaks, but this effect is less pronounced in $\mathrm{TiO}_{2} / \mathrm{C}$ and $\mathrm{TiO}_{2} / \mathrm{AC}$. The anatase content $(f(A))$ was determined from the integrated intensity of the anatase diffraction line (1 01$), I_{A}$, and that of the rutile diffraction line (1 110$), I_{R}$, using the following equation [24] and the results are listed in Table 1:

$$
f(A)=\frac{1}{1+12.6\left(I_{A} / I_{R}\right)} .
$$

The $f(A)$ values showed that the rutile phase is dominant in all of the prepared samples. Besides that, the crystallite size of the samples was calculated by applying the Scherrer equation on the plane (101) diffraction peak of anatase and

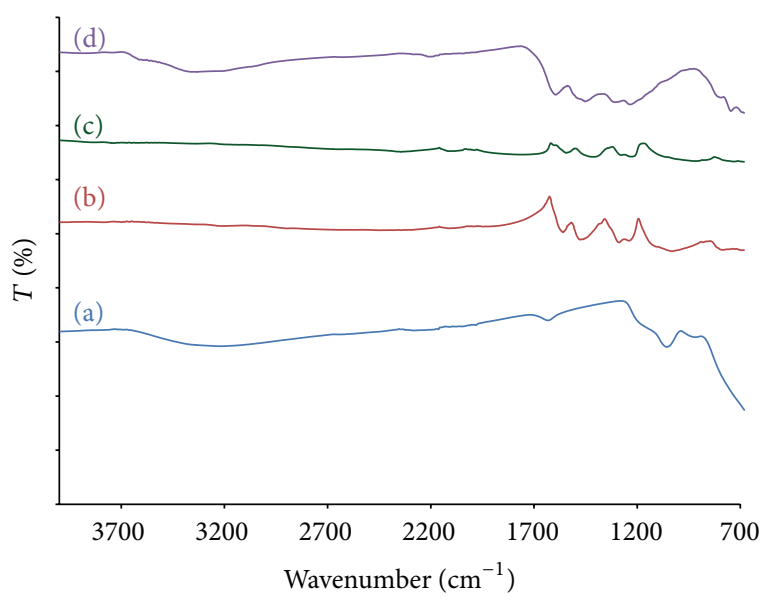

Figure 1: FTIR spectra of (a) $\mathrm{TiO}_{2}$, (b) Polyaniline, (c) $\mathrm{TiO}_{2} / \mathrm{PANi}$, and (d) $\mathrm{TiO}_{2} / \mathrm{AC}$, respectively.

(110) diffraction peak of rutile, as listed in Table 1. The BET surface area, pore size, micropore area, and volumes are listed in Table 1 as well. The results showed that the specific surface area adhered to the following order: $\mathrm{TiO}_{2} / \mathrm{AC}>\mathrm{TiO}_{2} / \mathrm{C}>$ $\mathrm{TiO}_{2} / \mathrm{PANi}>\mathrm{TiO}_{2}\left(179>134>54>9 \mathrm{~m}^{2} \mathrm{~g}^{-1}\right)$. This suggests that the characteristics of the composited catalyst were enhanced, as it provided more active sites for photocatalytic reactions to take place.

The thermal stability of the prepared $\mathrm{TiO}_{2} / \mathrm{PANi}$ and $\mathrm{TiO}_{2} / \mathrm{AC}$ was investigated and the TG-DTA analysis results are shown in Figure 5. The first weight loss took place in the range of temperature $50-120^{\circ} \mathrm{C}$ for $\mathrm{TiO}_{2} / \mathrm{PANi}$, which is $6.5 \%$ decrease from the original weight. The weight loss is due to the loss of moisture or water content, the evaporation of solvents such as ethanol and small molecules from the polymer matrix [25]. The second loss was determined at temperatures between 310 and $700^{\circ} \mathrm{C}$. During this step, the weight loss was attributed to the degradation of polyaniline main chain (about 54\%) [26-28]. At a temperature of about $700^{\circ} \mathrm{C}$, the PANi molecule was completely decomposed to carbon. The result showed that $\mathrm{TiO}_{2} / \mathrm{AC}$ has significantly improved thermal stabilities compared to $\mathrm{TiO}_{2} / \mathrm{PANi}$.

3.1. Evaluation of Photocatalytic Performance. The degradation of methylene blue (MB) was used in this work in order to evaluate the photocatalytic activity of the prepared samples. The effect of different loading percentages of $\mathrm{TiO}_{2}$ in activated carbon on photocatalytic activity has been investigated as well (Figure 6). The results showed that increasing the content of $\mathrm{TiO}_{2}$ improves photocatalytic performances. From the tests, it was determined that the $15 \% \mathrm{TiO}_{2}$ loading was to be further tested.

It is known that the concentration of methylene blue influences the photocatalytic performance of the samples [29]. Therefore, in this study, the photocatalytic activity of $\mathrm{TiO}_{2} / \mathrm{PANi}$ and $\mathrm{TiO}_{2} / \mathrm{AC}(0.05 \mathrm{mM})$ using different concentrations of $\mathrm{MB}$ within 90 minutes irradiation time was studied. It can be seen that $\mathrm{TiO}_{2}$ /activated carbon demonstrated 


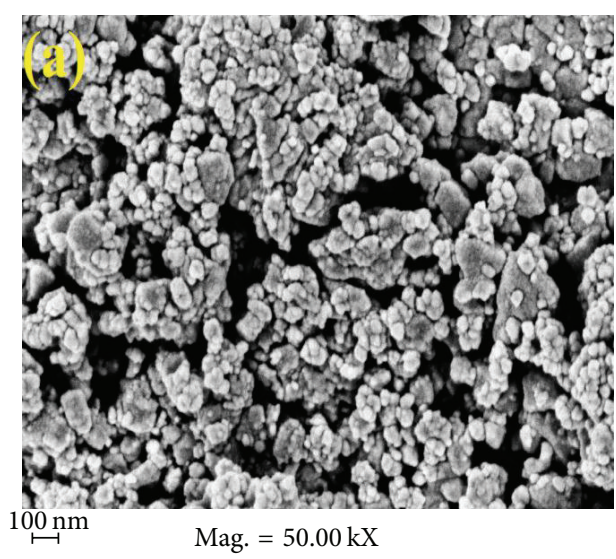

(a)

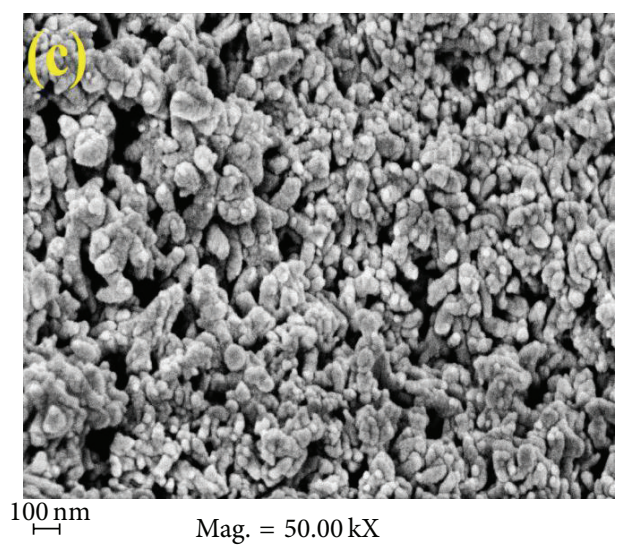

(c)

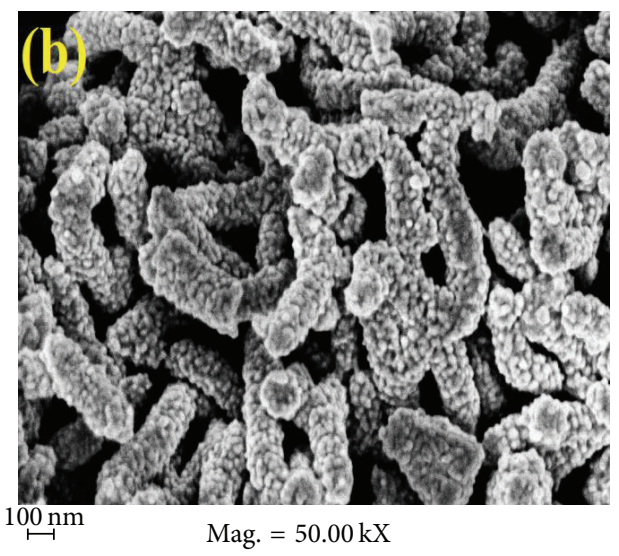

(b)

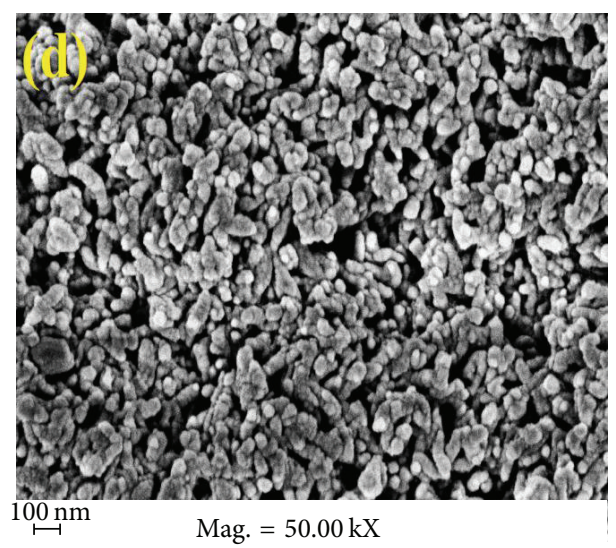

(d)

Figure 2: FESEM photographs of (a) $\mathrm{TiO}_{2}$ particles, (b) $\mathrm{TiO}_{2} / \mathrm{PANi}$, (c) $\mathrm{TiO}_{2} / \mathrm{C}$, and (d) $\mathrm{TiO}_{2} / \mathrm{AC}$, respectively.

TABLE 1: Texture properties of the $\mathrm{TiO}_{2}, \mathrm{TiO}_{2} / \mathrm{PANi}, \mathrm{TiO}_{2} / \mathrm{C}$, and $\mathrm{TiO}_{2} / \mathrm{AC}$ composites.

\begin{tabular}{lcccc}
\hline Physical properties & $\mathrm{TiO}_{2}$ & $\mathrm{TiO}_{2} / \mathrm{PANi}$ & $\mathrm{TiO}_{2} / \mathrm{C}$ & 134 \\
\hline Surface area $\left(\mathrm{m}^{2} / \mathrm{g}\right)$ & 8.55 & 53.73 & 9.26 & 178.57 \\
Pore size $(\mathrm{nm})$ & 9.48 & 13.8 & 29.33 & 6.79 \\
Micropore area $\left(\mathrm{m}^{2} / \mathrm{g}\right)$ & 3.34 & 8.22 & 0.015 & 76.62 \\
Micropore volume $\left(\mathrm{cm}^{3} / \mathrm{g}\right)$ & 0.001 & 0.004 & - & 0.037 \\
Crystallite size $^{\mathrm{a}}(\mathrm{nm})$ anatase & 25 & 14 & - & 11 \\
Crystallite size $^{\mathrm{a}}(\mathrm{nm})$ rutile & 48 & 19 & 0.087 & 20 \\
$f(A)^{\mathrm{b}}$ & 0.135 & 0.061 & 0.092 \\
\hline
\end{tabular}

${ }^{\mathrm{a}}$ Calculated by applying Scherrer's equation.

${ }^{\mathrm{b}}$ Anatase content calculated using (2).

superior photocatalytic activity for all different concentrations of MB (Figure 7).

The photocatalytic activity was also evaluated using irradiation time acting as its parameter (Figure 8). The result show rapid increase in $\mathrm{MB}$ degradation from 0 to 30 minutes which becomes slower after 30 minutes for both samples. The much higher $\mathrm{MB}$ degradation rate for $\mathrm{TiO}_{2} / \mathrm{AC}$ proves its better performance compared to $\mathrm{TiO}_{2} / \mathrm{PANi}$. $\mathrm{TiO}_{2} / \mathrm{AC}$ showed almost complete degradation of $\mathrm{MB}$ after 90 minutes of irradiation.
Figure 9 presents the result of the degradation of $\mathrm{MB}$ for bare $\mathrm{TiO}_{2}, \mathrm{TiO}_{2} / \mathrm{PANi}, \mathrm{TiO}_{2} / \mathrm{C}$, and $\mathrm{TiO}_{2} / \mathrm{AC}$. The experiment was carried out in 90-minute irradiation, and the concentration of methylene blue was $0.05 \mathrm{mM}$ for all samples. The degradation of $\mathrm{MB}$ without catalyst was used as a reference.

The results can be explained using texture properties of the prepared samples, as shown in Table 1 . The specific surface area, micropore area, and volume adhered to the trend $\mathrm{TiO}_{2} / \mathrm{AC}>\mathrm{TiO}_{2} / \mathrm{C}>\mathrm{TiO}_{2} / \mathrm{PANi}>\mathrm{TiO}_{2}$, which is 


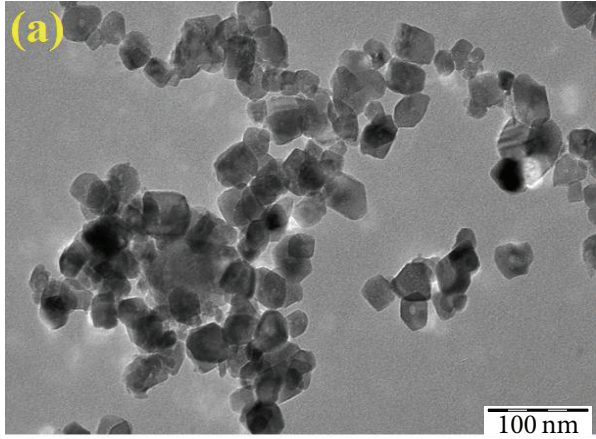

(a)

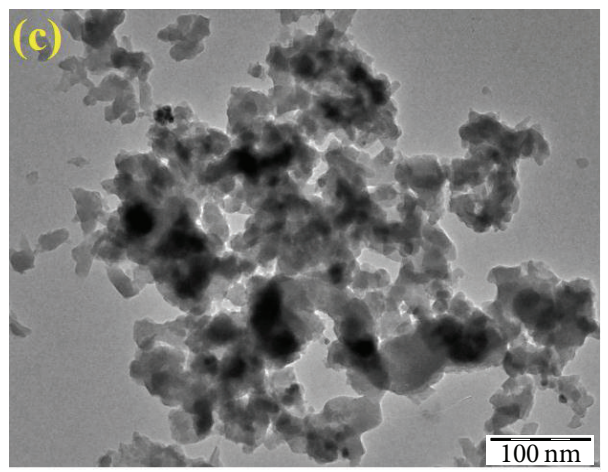

(c)

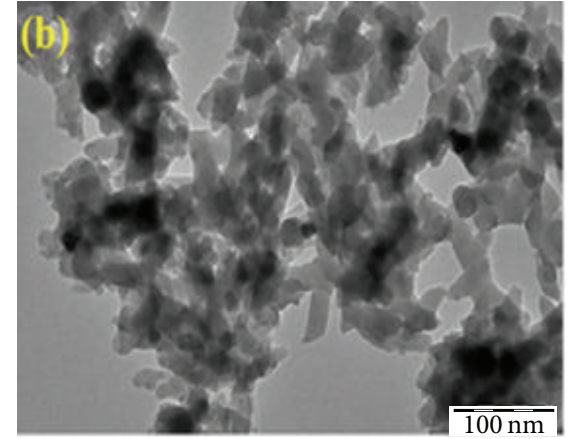

(b)

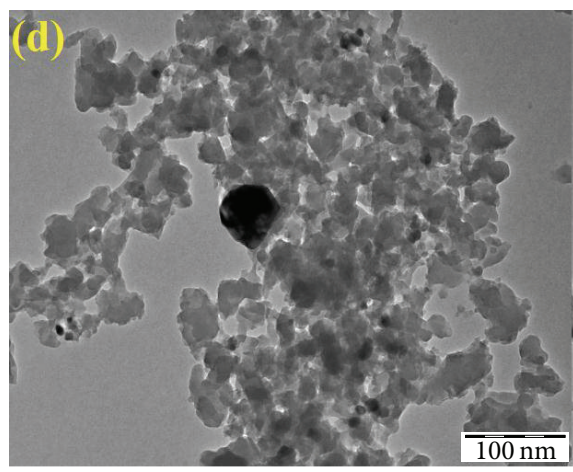

(d)

Figure 3: TEM photographs of (a) $\mathrm{TiO}_{2}$ particles, (b) $\mathrm{TiO}_{2} / \mathrm{PANi}$, (c) $\mathrm{TiO}_{2} / \mathrm{C}$, and (d) $\mathrm{TiO}_{2} / \mathrm{AC}$, respectively (magnification $45000 \mathrm{x}$ ).

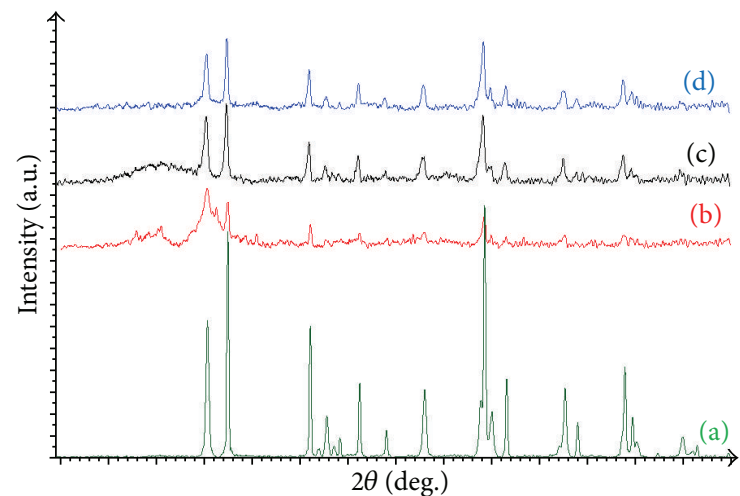

FIgURE 4: XRD patterns of samples. (a) $\mathrm{TiO}_{2}$ particles, (b) $\mathrm{TiO}_{2} / \mathrm{PANi}$, (c) $\mathrm{TiO}_{2} / \mathrm{C}$, and (d) $\mathrm{TiO}_{2} / \mathrm{AC}$, respectively.

similar to photocatalytic performance. This is attributed to the higher porosity of the activated carbon compered to others, which provide high adsorption capacity and more active sites for the reacting species during chemical reaction, which agrees with previous studies $[8,9,19,30-32]$. It was noted that the surface area of $\mathrm{TiO}_{2} / \mathrm{AC}$ is larger compared to the ones reported in the literature, which used polystyrene (PS) as a carbon source [33]. It also shows that PANi is a better source for the preparation of highly porous activated carbon.

On top of the synergistic effect for the mixture of $\mathrm{TiO}_{2}$ with activated carbon and highly porous structures, the

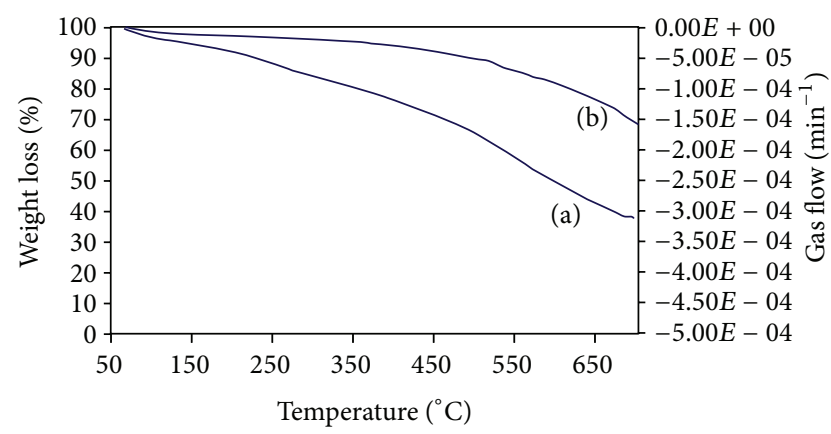

Figure 5: TGA thermogram analysis of (a) $\mathrm{TiO}_{2} / \mathrm{PANi}$ and (b) $\mathrm{TiO}_{2} / \mathrm{AC}$ composite.

high photocatalytic performance could be the result of the mixture of anatase and rutile phase of $\mathrm{TiO}_{2}$ in this work (Table 1). This can be explained by the synergic effect between anatase and rutile in $\mathrm{TiO}_{2}$ particles that are approximately close to each other, thus enhancing the activity [34]. This finding is in agreement with other studies reporting that the photocatalytic activity was enhanced when anatase and rutile were mixed $[34,35]$.

3.2. Recyclability of $\mathrm{TiO}_{2} / \mathrm{AC}$. Recyclability test was carried out for $\mathrm{TiO}_{2} / \mathrm{AC}$ to up to five cycles. The results are depicted in Figure 10, demonstrating good recyclability for the prepared composite. 


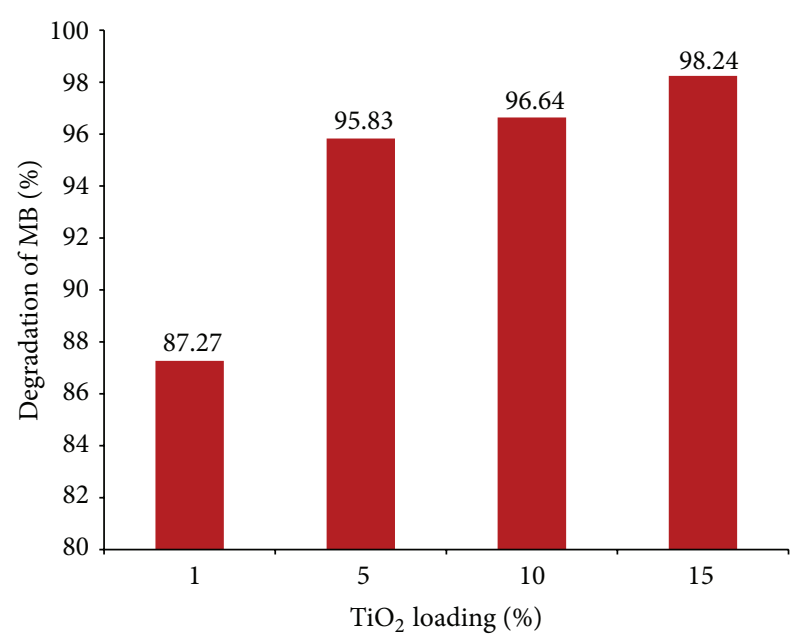

FIGURE 6: Effect of $\mathrm{TiO}_{2}$ loading (\%) on degradation of $\mathrm{MB}$ (under 90 minutes of UV light irradiation in room temperature).

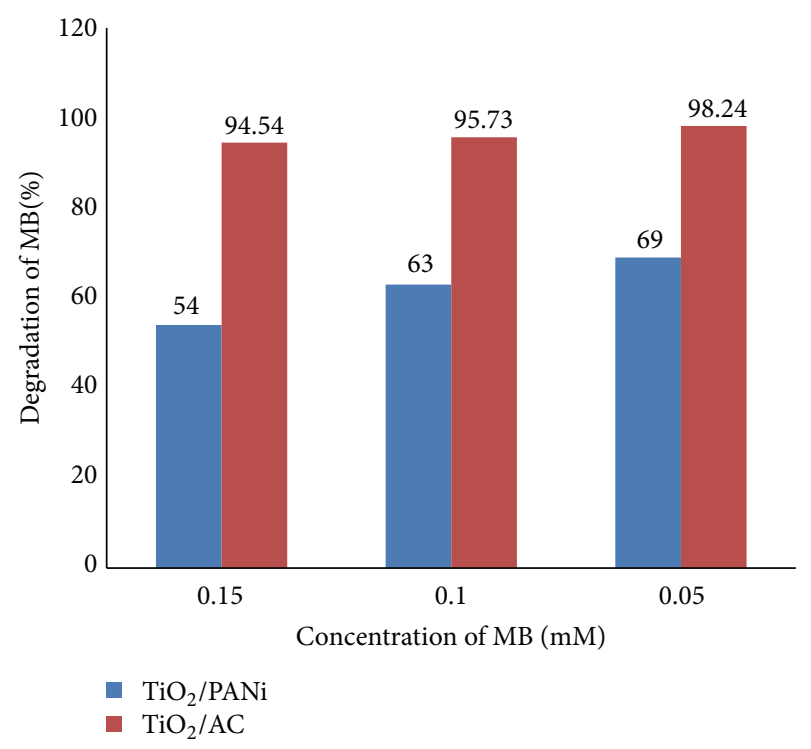

FIGURE 7: Effect of MB concentration on photocatalytic activity for $\mathrm{TiO}_{2} / \mathrm{PANi}$ and $\mathrm{TiO}_{2} / \mathrm{AC}$.

\section{Conclusion}

Regarding the possibility of photocatalytic improvement using a composite of $\mathrm{TiO}_{2}$, a different form of modified $\mathrm{TiO}_{2}$, namely, $\mathrm{TiO}_{2}$ /activated carbon (AC), $\mathrm{TiO}_{2} /$ Carbon (C), and $\mathrm{TiO}_{2} / \mathrm{PANi}$, were synthesized and characterized, and their catalytic performance have been studied. The effect of $\mathrm{TiO}_{2}$ loading, irradiation time, and $\mathrm{MB}$ concentration has been studied. $\mathrm{TiO}_{2} / \mathrm{AC}$ showed the highest porosity and photocatalytic performance compared to other composites. On top of considering the synergistic effect for the mixture of $\mathrm{TiO}_{2}$ with activated carbon and its high porosity, this high performance can also be attributed to the anatase and rutile mixture. Meanwhile, PANi demonstrated better AC source compared to previous works, and the recyclability

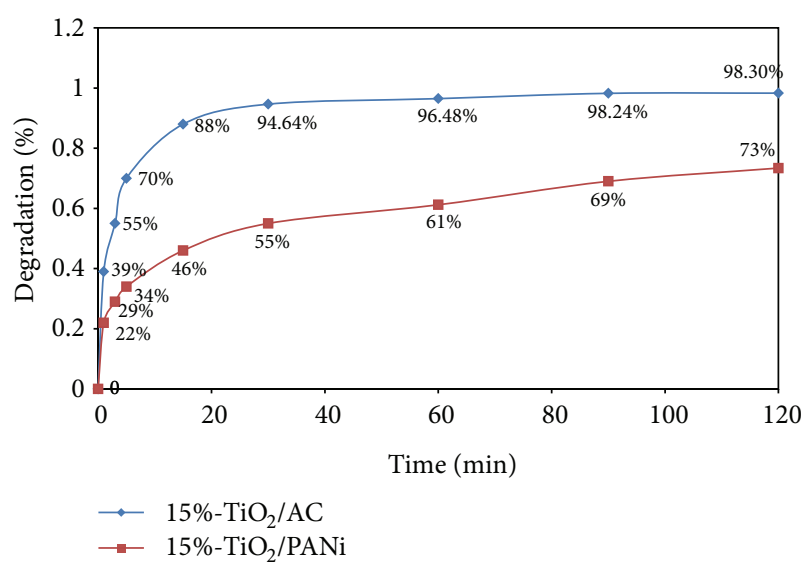

FIgURE 8: Photocatalytic activity: effect of irradiation time in degradation of $\mathrm{MB}$.

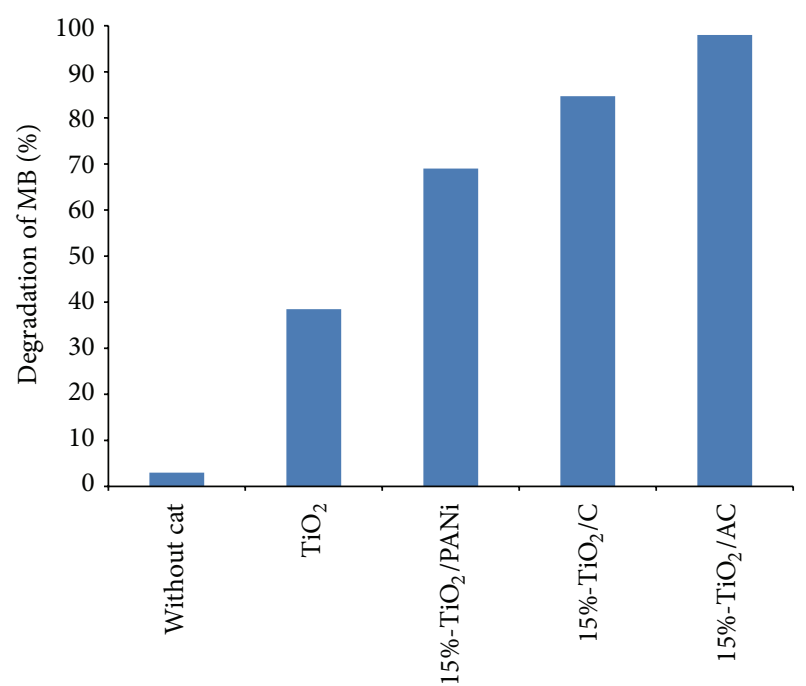

FIGURE 9: Photocatalytic degradation of methylene blue for bare $\mathrm{TiO}_{2}, \mathrm{TiO}_{2} / \mathrm{PANi}, \mathrm{TiO}_{2} / \mathrm{C}$, and $\mathrm{TiO}_{2} / \mathrm{AC}(0.05 \mathrm{mM} \mathrm{MB}$ and $90 \mathrm{~min}$ irradiation time).

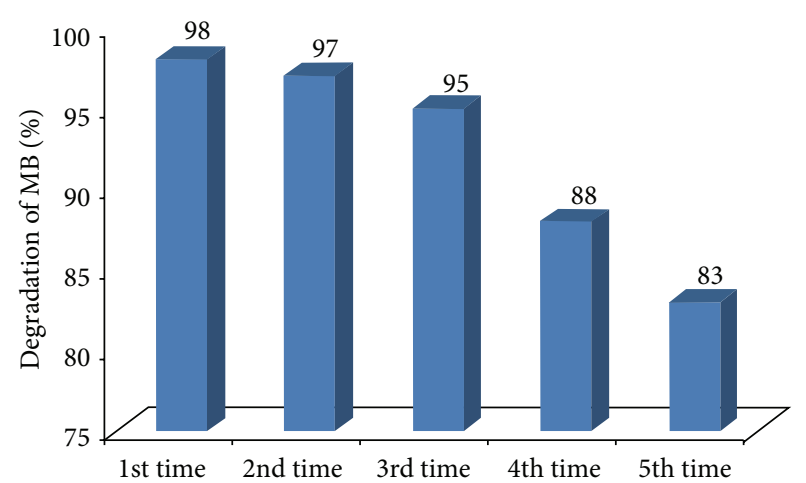

FIGURE 10: Recyclability of $\mathrm{TiO}_{2} / \mathrm{AC}$ was carried out for 5 cycles used. 
test demonstrated excellent performance for the synthesized composite.

\section{Conflict of Interests}

The authors declare that there is no conflict of interests regarding the publication of this paper.

\section{Acknowledgments}

The authors would like to acknowledge the financial support of the work by the Universiti Kebangsaan Malaysia for funding this project under the research Grants of Dana Impak Perdana (DLP-2013-015 and FRGS/1/2012/TK07/UKM/3/4) from Ministry of Higher Education (MOHE), Malaysia, and Centre of Research and Innovation Management (CRIM), UKM.

\section{References}

[1] S. Hussain, Z. Maqbool, S. Ali et al., "Biodecolorization of reactive black- 5 by a metal and salt tolerant bacterial strain Pseudomonas sp. RA20 isolated from Paharang drain effluents in Pakistan," Ecotoxicology and Environmental Safety, vol. 98, pp. 331-338, 2013.

[2] J. Zhao, C. Chen, and W. Ma, "Photocatalytic degradation of organic pollutants under visible light irradiation," Topics in Catalysis, vol. 35, pp. 269-278, 2005.

[3] D. Bahnemann, "Photocatalytic water treatment: solar energy applications," Solar Energy, vol. 77, no. 5, pp. 445-459, 2004.

[4] U. I. Gaya and A. H. Abdullah, "Heterogeneous photocatalytic degradation of organic contaminants over titanium dioxide: a review of fundamentals, progress and problems," Journal of Photochemistry and Photobiology C: Photochemistry Reviews, vol. 9, no. 1, pp. 1-12, 2008.

[5] M. R. Hoffmann, S. T. Martin, W. Choi, and D. W. Bahnemann, "Environmental applications of semiconductor photocatalysis," Chemical Reviews, vol. 95, no. 1, pp. 69-96, 1995.

[6] O. Carp, C. L. Huisman, and A. Reller, "Photoinduced reactivity of titanium dioxide," Progress in Solid State Chemistry, vol. 32, no. 1-2, pp. 33-177, 2004.

[7] T. Tachikawa, M. Fujitsuka, and T. Majima, "Mechanistic insight into the $\mathrm{TiO}_{2}$ photocatalytic reactions: design of new photocatalysts," Journal of Physical Chemistry C, vol. 111, no. 14, pp. 5259-5275, 2007.

[8] S. X. Liu, X. Y. Chen, and X. Chen, "A $\mathrm{TiO}_{2} / \mathrm{AC}$ composite photocatalyst with high activity and easy separation prepared by a hydrothermal method," Journal of Hazardous Materials, vol. 143, no. 1-2, pp. 257-263, 2007.

[9] L. F. Velasco, J. B. Parra, and C. O. Ania, "Role of activated carbon features on the photocatalytic degradation of phenol," Applied Surface Science, vol. 256, no. 17, pp. 5254-5258, 2010.

[10] W. N. R. W. Isahak, M. W. M. Hisham, and M. A. Yarmo, "Highly porous carbon materials from biomass by chemical and carbonization method: a comparison study," Journal of Chemistry, vol. 2013, Article ID 620346, 6 pages, 2013.

[11] T. Torimoto, Y. Okawa, N. Takeda, and H. Yoneyama, "Effect of activated carbon content in $\mathrm{TiO}_{2}$-loaded activated carbon on photodegradation behaviors of dichloromethane," Journal of Photochemistry and Photobiology A: Chemistry, vol. 103, no. 1-2, pp. 153-157, 1997.
[12] B. Tryba, "Increase of the photocatalytic activity of $\mathrm{TiO}_{2}$ by carbon and iron modifications," International Journal of Photoenergy, vol. 2008, Article ID 721824, 15 pages, 2008.

[13] J. Matos, J. Laine, and J. Herrmann, "Association of activated carbons of different origins with titania in the photocatalytic purification of water," Carbon, vol. 37, no. 11, pp. 1870-1872, 1999.

[14] J. Araña, J. M. Doña-Rodríguez, E. Tello Rendón et al., “ $\mathrm{TiO}_{2}$ activation by using activated carbon as a support: part I. Surface characterisation and decantability study," Applied Catalysis B: Environmental, vol. 44, pp. 161-172, 2003.

[15] J. Araña, J. M. Doña-Rodríguez, E. Tello Rendón et al., “ $\mathrm{TiO}_{2}$ activation by using activated carbon as a support: part II. Photoreactivity and FTIR study," Applied Catalysis B: Environmental, vol. 44, pp. 153-160, 2003.

[16] S. Brunauer, P. H. Emmett, and E. Teller, "Adsorption of gases in multimolecular layers," Journal of the American Chemical Society, vol. 60, no. 2, pp. 309-319, 1938.

[17] E. P. Barrett, L. G. Joyner, and P. P. Halenda, "The determination of pore volume and area distributions in porous substances. I. Computations from nitrogen isotherms," Journal of the American Chemical Society, vol. 73, no. 1, pp. 373-380, 1951.

[18] G. Liu, T. Wu, J. Zhao, H. Hidaka, and N. Serpone, "Photoassisted degradation of dye pollutants. 8. Irreversible degradation of alizarin red under visible light radiation in air-equilibrated aqueous $\mathrm{TiO}_{2}$ dispersions," Environmental Science and Technology, vol. 33, no. 12, pp. 2081-2087, 1999.

[19] B. Tryba, A. W. Morawski, and M. Inagaki, "Application of $\mathrm{TiO}_{2}$ mounted activated carbon to the removal of phenol from water," Applied Catalysis B: Environmental, vol. 41, no. 4, pp. 427-433, 2003.

[20] J. Ovenstone, "Preparation of novel titania photocatalysts with high activity," Journal of Materials Science, vol. 36, no. 6, pp. 1325-1329, 2001.

[21] J. Moon, H. Takagi, Y. Fujishiro, and M. Awano, "Preparation and characterization of the Sb-doped $\mathrm{TiO}_{2}$ photocatalysts," Journal of Materials Science, vol. 36, no. 4, pp. 949-955, 2001.

[22] S. S. Arbuj, R. R. Hawaldar, U. P. Mulik, B. N. Wani, D. P. Amalnerkar, and S. B. Waghmode, "Preparation, characterization and photocatalytic activity of $\mathrm{TiO}_{2}$ towards methylene blue degradation," Materials Science and Engineering B: Solid-State Materials for Advanced Technology, vol. 168, no. 1, pp. 90-94, 2010.

[23] M. Toyoda, Y. Nanbu, Y. Nakazawa, M. Hirano, and M. Inagaki, "Effect of crystallinity of anatase on photoactivity for methyleneblue decomposition in water," Applied Catalysis B: Environmental, vol. 49, no. 4, pp. 227-232, 2004.

[24] R. A. Spurr, "Quantitative analysis of anatase-rutile mixtures with an X-ray diffractometer," Analytical Chemistry, vol. 29, no. 5, pp. 760-762, 1957.

[25] A. H. Elsayed, M. S. Mohy Eldin, A. M. Elsyed, A. H. Abo Elazm, E. M. Younes, and H. A. Motaweh, "Synthesis and properties of polyaniline/ferrites nanocomposites," International Journal of Electrochemical Science, vol. 6, no. 1, pp. 206-221, 2011.

[26] J. Deng, X. Ding, W. Zhang et al., "Magnetic and conducting $\mathrm{Fe}_{3} \mathrm{O}_{4}$-cross-linked polyaniline nanoparticles with core-shell structure," Polymer, vol. 43, no. 8, pp. 2179-2184, 2002.

[27] N. Asim, S. Radiman, and M. A. B. Yarmo, "Preparation and characterization of core-shell polyaniline $/ \mathrm{V}_{2} \mathrm{O}_{5}$ nanocomposite via microemulsion method," Materials Letters, vol. 62, no. 6-7, pp. 1044-1047, 2008. 
[28] S. Lee, Y. Chen, C. Ho, C. Chang, and Y. Hong, "A study on synthesis and characterization of the core-shell materials of $\mathrm{Mn}_{1-x} \mathrm{Zn}_{x} \mathrm{Fe}_{2} \mathrm{O}_{4}$-polyaniline," Materials Science and Engineering B: Solid-State Materials for Advanced Technology, vol. 143, no. 1-3, pp. 1-6, 2007.

[29] R. M. Mohamed, I. A. Mkhalid, E. S. Baeissa, and M. A. Al-Rayyani, "Photocatalytic degradation of methylene blue by $\mathrm{Fe} / \mathrm{ZnO} / \mathrm{SiO}_{2}$ nanoparticles under visiblelight," Journal of Nanotechnology, vol. 2012, Article ID 329082, 5 pages, 2012.

[30] Y. Li, S. Zhang, Q. Yu, and W. Yin, "The effects of activated carbon supports on the structure and properties of $\mathrm{TiO}_{2}$ nanoparticles prepared by a sol-gel method," Applied Surface Science, vol. 253, no. 23, pp. 9254-9258, 2007.

[31] X. Wang, Z. Hu, Y. Chen, G. Zhao, Y. Liu, and Z. Wen, "A novel approach towards high-performance composite photocatalyst of $\mathrm{TiO}_{2}$ deposited on activated carbon," Applied Surface Science, vol. 255, no. 7, pp. 3953-3958, 2009.

[32] X. Zhang, M. Zhou, and L. Lei, "Preparation of photocatalytic $\mathrm{TiO}_{2}$ coatings of nanosized particles on activated carbon by APMOCVD," Carbon, vol. 43, no. 8, pp. 1700-1708, 2005.

[33] S. Lubis, L. Yuliati, S. L. Lee, I. Sumpono, and H. Nur, "Improvement of catalytic activity in styrene oxidation of carbon-coated titania by formation of porous carbon layer," Chemical Engineering Journal, vol. 209, pp. 486-493, 2012.

[34] T. Ohno, K. Tokieda, S. Higashida, and M. Matsumura, "Synergism between rutile and anatase $\mathrm{TiO}_{2}$ particles in photocatalytic oxidation of naphthalene," Applied Catalysis A: General, vol. 244, no. 2, pp. 383-391, 2003.

[35] C. Wu, Y. Yue, X. Deng, W. Hua, and Z. Gao, "Investigation on the synergetic effect between anatase and rutile nanoparticles in gas-phase photocatalytic oxidations," Catalysis Today, vol. 9395, pp. 863-869, 2004. 

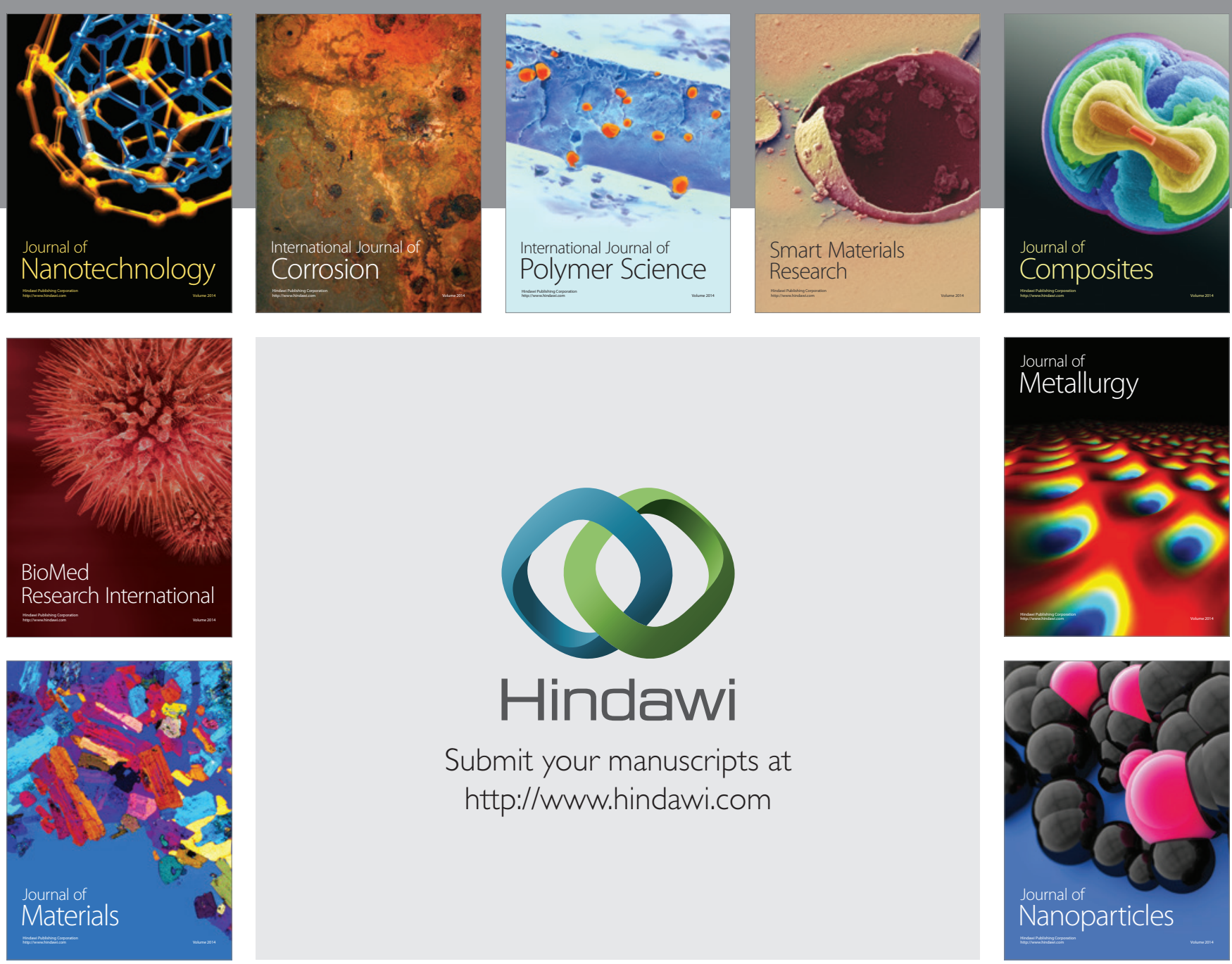

Submit your manuscripts at http://www.hindawi.com
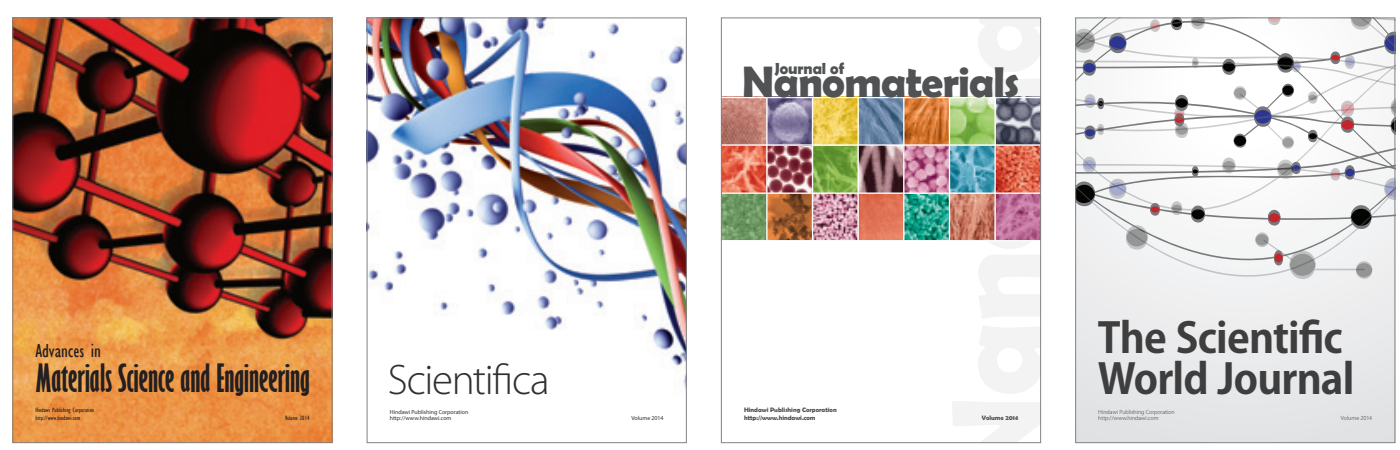

\section{The Scientific World Journal}
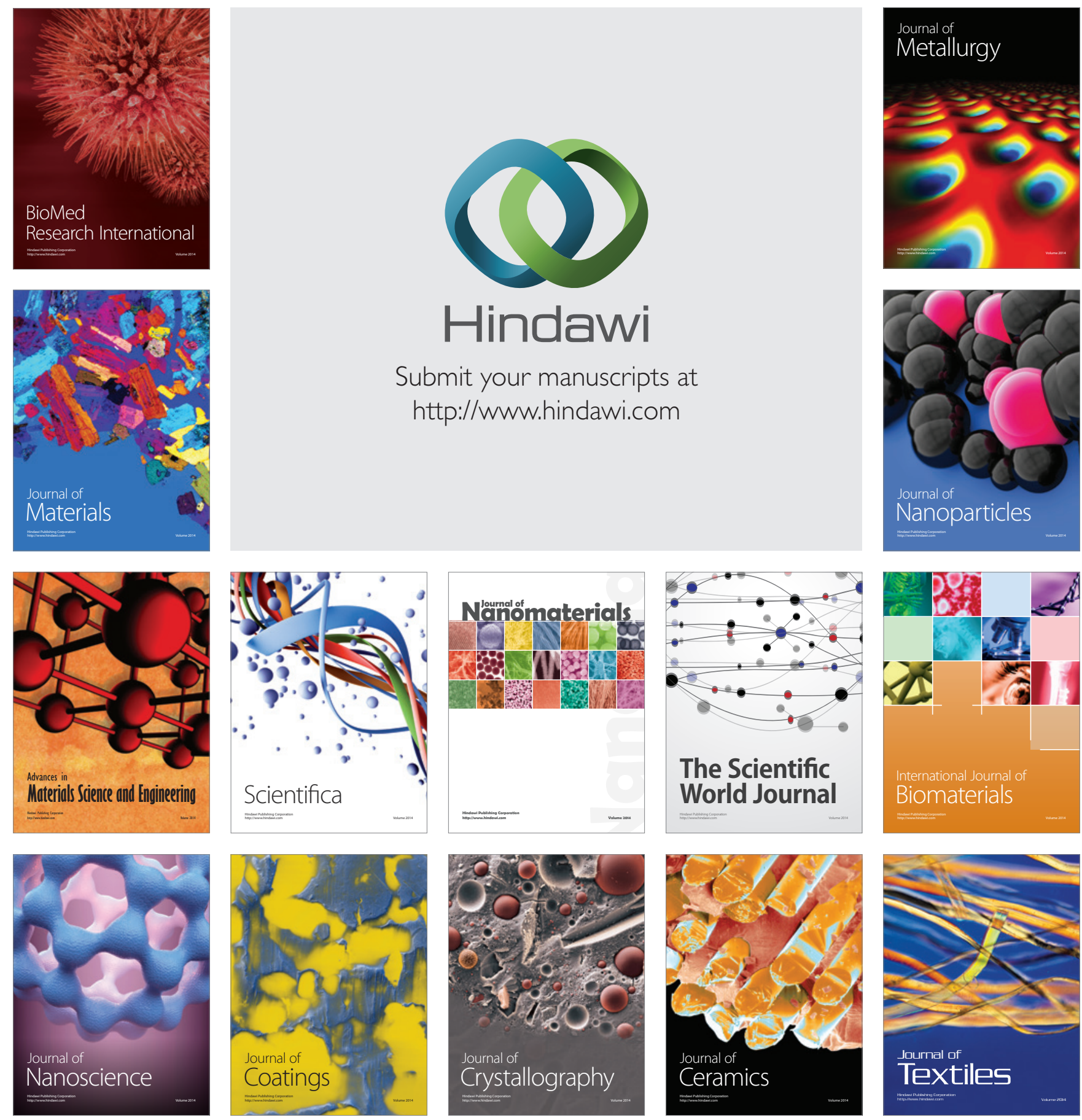